\title{
Programa Institucional de Bolsa de Iniciação à Docência - PIBID: um estudo exploratório
}

\author{
Institutional Program for Scholarships for Initiation in Teaching - PIBID: an exploratory study \\ Programme Institutionnel de Bourse d'initiation à l'enseignement - PIBID : une étude exploratoire
}

Elizabeth Gottschalg Raimann ${ }^{1}$

Universidade. Federal de Goiás

Juliana Alves da Guarda².

\begin{abstract}
Resumo: No contexto da política de formação de professores, dentre várias ações governamentais está o Programa Institucional de Bolsa de Iniciação à Docência (PIBID), implementado a partir do Plano de Desenvolvimento da Educação (PDE) e na atual conjuntura da política nacional de formação de professores a proposta de sua "modernização" a partir do programa de residência pedagógica. Este artigo tem como objetivo apresentar um estudo exploratório sobre as produções do PIBID, tendo como questão norteadora: o que as pesquisas revelam sobre a contribuição do PIBID na formação dos egressos? O levantamento foi realizado no banco de dados da Coordenação de Aperfeiçoamento de Pessoal de Nível Superior - CAPES entre os anos de 2013 a 2017. Os dados identificaram 17 produções, sendo 16 dissertações e uma tese. A maior produção ocorreu no ano de 2016, sendo 88\% provenientes de instituições públicas. O sudeste apresentou oito produções, seguidas pelo nordeste e sul com quatro respectivamente. A região centro-oeste com apenas uma produção. Todas as pesquisas apontaram que o programa contribui na formação dos egressos, levando inclusive a opção pela docência por parte de alguns. Por outro lado, algumas destacaram as limitações do programa quanto à desvalorização da profissão e a necessidade de se repensar às ações do PIBID.
\end{abstract}

Palavras-chave: Política educacional. Formação de professores. PIBID.

Abstract: In the context of the teacher formation policy, among several governmental actions is the Institutional Program for Scholarships for Initiation in Teaching (PIBID), implemented from the Education Development Plan (PDE) and in the current context of the national policy of teachers' formation, the proposal of its "modernization" from the pedagogical residency program. This present research aims to expose an exploratory study about the productions of the PIBID, with the guiding question: what do surveys reveal about the contribution of PIBID to the formation of graduates? The survey was carried out in the database of the Coordination for the Improvement of Higher Education Personnel CAPES between the years of 2013 to 2017. Data identified 17 productions, being 16 dissertations and a thesis. The highest production occurred in 2016, with $88 \%$ coming from public institutions. The Southeast region presented eight productions, followed by Northeast and South with four respectively. The Midwest region presented only one

\footnotetext{
${ }^{1}$ Doutora em educação pela Universidade Federal de Uberlândia. Professora da Universidade. Federal de Goiás (UFG), Regional Jataí. E-mail: elizabethraimann@gmail.com .

2 Mestranda em educação no Programa de Pós-Graduação da Universidade Federal de Goiás/Regional Jataí. E-mail: julianaalvesjti@gmail.com
} 
production. All the researches pointed out that the program contributes to the formation of the graduates, including the option of teaching by some. On the other hand, some of them highlighted the limitations of the program regarding the devaluation of the profession and the need to rethink the actions of PIBID.

Keywords: Educational policy. Teacher training. PIBID.

Résumé : Dans le contexte de la politique de formation des enseignants, parmi plusieurs actions gouvernementales, il y a le Programme institutionnel d'initiation à l'enseignement (PIBID), mis en ouvre à partir du Plan de développement de l'éducation (PDE). Considérant le contexte actuel de la politique nationale de formation des enseignants, on a la proposition de leur «modernisation » comme programme de résidence pédagogique. Cet article a pour but de présenter une étude exploratoire sur les productions du PIBID, avec la question centrale : que révèlent les enquêtes sur la contribution du PIBID à la formation des diplômés ? L'enquête a été réalisée dans la base de données de la Coordination de l'amélioration du personnel de l'enseignement supérieur - CAPES -, entre les années 2013 et 2017. Le résultat a identifié 17 productions, soit 16 dissertations et une thèse. La production la plus élevée a eu lieu en 2016, 88\% provenant d'institutions publiques. Le Sud-Est a présenté huit productions, suivies du Nord et du Sud avec quatre respectivement, et la région du Centre Ouest n'avait qu'une seule production. Toutes les recherches ont montré que le PIBID contribue à la formation des diplômés, y compris pour prendre la décision de suivre une carrière d'enseignant par certains. D'un autre côté, certains ont souligné les limites du programme concernant le manque de valorisation professionnelle et la nécessité de repenser les actions du PIBID.

Mots-clés : Politique éducative. Formation des enseignants PIBID.

\section{Introdução}

Este artigo apresenta parte do resultado de pesquisa em andamento, no mestrado em educação, cujo objeto de estudo é o Programa Institucional de Bolsa de Iniciação à Docência (PIBID) e seus desdobramentos na vida profissional dos bolsistas egressos. No intuito de levantar o estado do conhecimento sobre o PIBID, teve-se a seguinte questão norteadora: o que as pesquisas revelam sobre a contribuição do Programa na formação de professores e, em específico, os egressos estão atuando na educação básica? Como procedimento metodológico recorreu-se ao Banco de Teses e Dissertações da CAPES, identificando as produções científicas que abordam o tema PIBID e a atuação dos egressos na educação básica.

As pesquisas denominadas por "Estado do conhecimento" buscam mapear e discutir as produções científicas sobre determinada temática. Ferreira (2002), ao fazer um estudo 
sobre esse tipo de pesquisa afirma que os pesquisadores são: "Sustentados e movidos pelo desafio de conhecer o já construído e produzido para depois buscar o que ainda não foi feito [...]” (FERREIRA, 2002, p. 259). A autora destaca que essas pesquisas são uma opção metodológica para os trabalhos científicos e permitem realizar o levantamento e a avaliação do conhecimento sobre algum tema. Esse levantamento constitui a fase inicial para uma investigação do objeto de estudo, pois aponta o que os pesquisadores têm estudado sobre o tema de interesse, nesse caso o PIBID e sua contribuição na vida profissional dos egressos.

O programa foi implementado a partir de 2007, assim é importante destacar que as pesquisas que tratam da sua contribuição na formação dos egressos aparecem somente a partir de 2013 no banco de dados da CAPES. Desta forma, o recorte temporal foi entre 2013 a 2017 , e o levantamento das pesquisas até junho de 2017.

A exposição apresenta, em primeiro lugar, o PIBID como um programa de formação inicial de professores, dando ênfase à Portaria $n^{\circ} 38$, de 12 de dezembro de 2007 e à Portaria n 096 de 18 de julho de 2013 que dispõem sobre o programa. Na sequência, a exposição traz o resultado do levantamento junto ao banco de dados da CAPES e sua análise e, por fim, as considerações finais, apontando para as principais conclusões frente à temática.

\section{O Programa Institucional de Bolsas de Iniciação a Docência- PIBID}

O Programa Institucional de Bolsa de Iniciação à Docência, previsto no Plano de Desenvolvimento da Educação (PDE), foi proposto como um programa de valorização da formação inicial de professores em nível superior e de incentivo ao magistério, contribuindo, assim, para a qualidade da educação básica das escolas públicas.

O PDE, por sua vez, objetivou melhorar a qualidade do ensino do país e apresentar programas voltados para a educação básica, educação superior, educação profissional e alfabetização (BRASIL, 2008).

O PIBID inicialmente teve como proposta atender as áreas de Biologia, Física, Matemática e Química, considerando a carência de professores em exercício nessas disciplinas específicas (BRASIL, 2008). O investimento ficou por conta de bolsas remuneradas para os estudantes desses cursos de licenciatura, para o professor da universidade, coordenador de área, e para o professor, supervisor, da escola pública. Previa a promoção da parceria entre universidade e escola, articulando a formação inicial e continuada, tendo como intuito melhorar a educação básica, mediante a formação inicial que 
se dá no ensino superior, e, ao mesmo tempo, contribuir na formação continuada dos professores da escola pública e dos coordenadores do programa que atuam no ensino superior (GATTI et. al, 2011).

Inicialmente a participação no programa exigia a elaboração de projetos de intervenção desenvolvidos por licenciandos na escola, tendo como critério, a condição de a escola estar abaixo da média nacional no Índice de Desenvolvimento da Educação Básica (IDEB) (BRASIL, 2007).

Com a Portaria nº 096, de 18 de julho de 2013 esse critério de seleção das escolas foi ampliado, assim, as instituições deveriam desenvolver projetos em escola que:

[...] tenham obtido Índice de Desenvolvimento da Educação Básica (Ideb) abaixo da média nacional e naquelas que tenham experiências bem sucedidas de ensino e aprendizagem, a fim de apreender as diferentes realidades e necessidades da educação básica e de contribuir para a elevação do Ideb, compreendendo-o nos seus aspectos descritivos, limites e possibilidades (BRASIL, 2013. p. 4).

Estes projetos, por sua vez, prevêem atividades pedagógicas orientadas pelo professor do ensino superior e supervisionadas por um professor da escola pública de atuação do projeto (BRASIL. 2013).

Considerando tais questões, a Portaria $n^{\circ}$ 38, de 12 de dezembro de 2007, apresenta o primeiro edital do programa, contemplando as áreas de biologia, física, química e matemática com os seguintes objetivos:

I - incentivar a formação de professores para a educação básica, especialmente para o ensino médio;

II - valorizar o magistério, incentivando os estudantes que optam pela carreira docente;

III - promover a melhoria da qualidade da educação básica;

IV - promover a articulação integrada da educação superior do sistema federal com a educação básica do sistema público, em proveito de uma sólida formação docente inicial;

V - elevar a qualidade das ações acadêmicas voltadas à formação (BRASIL, 2007, p. 1).

A partir de 2009, as demais licenciaturas foram contempladas e, ao mesmo tempo, em consonância com o decreto n. ${ }^{\circ} 6.755$ de 2009, que instituía a política nacional de formação de profissionais do magistério da educação básica (BRASIL, 2009), a finalidade do PIBID foi ampliada. Almejava-se, mediante a integração entre a universidade e a escola básica, não apenas a qualidade da formação dos professores, mas também a qualidade da educação pública buscando articular teoria e prática e contribuir com a valorização do magistério. 
Desta forma, os licenciandos, ao participarem da cultura escolar de uma forma intensa, poderiam conhecer o cotidiano escolar, vivenciar as dificuldades e participar de processos inovadores para melhorar o processo de ensino-aprendizagem. A interação junto aos professores da escola promoveria também uma formação continuada desses profissionais. Eram as metas:

I - incentivar a formação de docentes em nível superior para a educação básica;

II - contribuir para a valorização do magistério;

III - elevar a qualidade da formação inicial de professores nos cursos de licenciatura, promovendo a integração entre educação superior e educação básica; IV - inserir os licenciandos no cotidiano de escolas da rede pública de educação, proporcionando-lhes oportunidades de criação e participação em experiências metodológicas, tecnológicas e práticas docentes de caráter inovador e interdisciplinar que busquem a superação de problemas identificados no processo de ensino aprendizagem;

V - incentivar escolas públicas de educação básica, mobilizando seus professores como co-formadores dos futuros docentes e tornando-as protagonistas nos processos de formação inicial para o magistério;

VI - contribuir para a articulação entre teoria e prática necessárias à formação dos docentes, elevando a qualidade das ações acadêmicas nos cursos de licenciatura;

VII - contribuir para que os estudantes de licenciatura se insiram na cultura escolar do magistério, por meio da apropriação e da reflexão sobre instrumentos, saberes e peculiaridades do trabalho docente (BRASIL, 2013, p. $2-3)$.

A partir dos objetivos apresentados acima, com a proposta ampliada do programa, as diferentes licenciaturas passaram a ser contempladas e a CAPES assumiria então a responsabilidade pela política nacional de formação de professores. Posteriormente, este decreto de n. ${ }^{\circ}$ 6.755/2009 foi substituído pelo n. ${ }^{\circ}$ 8.752/2016 (BRASIL, 2016), adequando a política nacional de formação dos profissionais da educação básica às metas 15 e 16 do Plano Nacional de Educação (PNE) (2014-2014).

Guarda e Raimann (2016), ao analisarem o PIBID, apontavam para a possibilidade de ele se tornar um programa de Estado e não apenas de governo, pois diante da aprovação do novo PNE (2014 - 2024), estava previsto na meta 15, ampliar programas de iniciação à docência nos cursos de licenciaturas para incentivar a formação de professores para que estes exercessem a profissão na educação básica. Por outro lado, as autoras apontavam para algumas limitações, dentre elas, a participação restrita dos licenciandos, ou seja, nem todos os alunos receberiam bolsa, pois havia especificidades no critério de seleção, a meritocracia e a redução, por parte do governo federal, quanto aos investimentos comprometendo a sua continuidade a partir do ano de 2015. 
Quanto à questão na meritocracia, fica claro no art. 36 da Portaria $n^{\circ}$ 096, de 18 de julho de 2013 quando apresenta alguns requisitos aos bolsistas "possuir bom desempenho acadêmico, evidenciado pelo histórico escolar consoante as normas da IES” (BRASIL, 2013. p. 13).

Atualmente, o PIBID passa por uma reestruturação ou "modernização" como quer chamar o Ministério da Educação (MEC). Atrelado à proposta do Programa de Residência Pedagógica (PRP), o MEC busca adequar a formação de professores à Base Nacional Comum Curricular (BNCC). Esta iniciativa recebeu severas críticas e nota de repúdio por parte de entidades como ANPED (Associação Nacional de Pós-Graduação e Pesquisa em Educação), ANFOPE (Associação Nacional pela Formação dos Profissionais da Educação), ANPAE (Associação Nacional de Política e Administração da Educação), CNTE (Confederação Nacional dos Trabalhadores em Educação), dentre outras. Na avaliação realizada, entenderam que o conteúdo dos editais da CAPES números 06 e 07 de 2018, que tratam do PRP e PIBID, nada mais são do que padronização e controle da formação de professores (ANPED, 2018).

Diante do contexto atual, e ao se pretender associar o PIBID ao Programa de Residência Pedagógica, o cenário não se apresenta dos melhores, mais lutas virão!

\section{A contribuição do PIBID na formação de professores egressos: o que os dados apresentam?}

No intuito de conhecer a existência de pesquisas, que tratam do PIBID e sua contribuição da formação de professores egressos ao programa, fez-se um levantamento de produções científicas junto o Banco de Teses e Dissertações da CAPES, tendo como recorte temporal os anos de 2013 a 2017, pois a partir de 2013 já se é possível encontrar egressos do programa.

Como metodologia de busca, utilizou-se a combinação "Programa Institucional de Bolsa de Iniciação à Docência” e, como resultado, encontraram-se 987.085 trabalhos. Entende-se que o sistema de busca online, faz um mapeamento de todos os estudos que contêm as palavras utilizadas no termo mencionado. Assim, com o intuito de buscar somente trabalhos que tratam da contribuição do programa na formação dos egressos, foi necessário refinar as buscas para o termo "PIBID AND EGRESSOS”. Foram encontrados 37 trabalhos, incluindo teses e dissertações, que tratam do PIBID e dos egressos do programa. 
Ao analisar os resumos, foram encontradas 30 dissertações, incluindo aquelas feitas na condição de mestrado profissionalizante, e ainda sete teses. Procurou-se desenvolver uma leitura dos resumos para verificar quais os trabalhos que tratavam do PIBID e as contribuições na formação dos egressos. Da análise realizada envolvendo dissertações e teses, 17 produções se aproximaram do objeto de estudo, sendo 16 dissertações e uma tese, como se observa na tabela abaixo:

Tabela 1 - Dissertações e teses sobre PIBID por autor, instituição de ensino superior, programa de pós - graduação, linha de pesquisa, ano de publicação e tipo de pesquisa.

\begin{tabular}{|c|c|c|c|c|c|}
\hline Autor & $\begin{array}{l}\text { Instituição } \\
\text { de ensino } \\
\text { superior }\end{array}$ & $\begin{array}{l}\text { Programa de } \\
\text { Pós- } \\
\text { graduação }\end{array}$ & $\begin{array}{l}\text { Linha de } \\
\text { pesquisa }\end{array}$ & Ano & $\begin{array}{l}\text { Tipo de } \\
\text { pesquisa }\end{array}$ \\
\hline $\begin{array}{l}\text { MARTINS, } \\
\text { Maria Márcia }\end{array}$ & $\begin{array}{c}\text { Universidade } \\
\text { Federal do } \\
\text { Ceará }\end{array}$ & $\begin{array}{c}\text { Mestrado } \\
\text { Profissional } \\
\text { em Ensino de } \\
\text { Ciências e } \\
\text { Matemática }\end{array}$ & $\begin{array}{c}\text { Métodos } \\
\text { pedagógicos no } \\
\text { ensino de ciências }\end{array}$ & 2013 & Dissertação \\
\hline $\begin{array}{l}\text { OLIVEIRA, } \\
\text { Maximiliano }\end{array}$ & $\begin{array}{l}\text { Universidade } \\
\text { Federal de } \\
\text { São João del- } \\
\text { Rei }\end{array}$ & Educação & $\begin{array}{c}\text { Discursos e } \\
\text { produção de } \\
\text { saberes nas } \\
\text { práticas } \\
\text { educativas }\end{array}$ & 2014 & Dissertação \\
\hline $\begin{array}{c}\text { OLIVERI, } \\
\text { Andressa }\end{array}$ & $\begin{array}{c}\text { Universidade } \\
\text { Federal de } \\
\text { Ouro Preto }\end{array}$ & Educação & $\begin{array}{l}\text { Formação de } \\
\text { professores, } \\
\text { instituições e } \\
\text { história da } \\
\text { educação }\end{array}$ & 2014 & Dissertação \\
\hline $\begin{array}{l}\text { SILVA, } \\
\text { Danielli }\end{array}$ & $\begin{array}{l}\text { Universidade } \\
\text { Federal de } \\
\text { São Carlos }\end{array}$ & Educação & $\begin{array}{l}\text { Educação em } \\
\text { ciências e } \\
\text { matemática }\end{array}$ & 2014 & Dissertação \\
\hline $\begin{array}{l}\text { ARAÚJJO, } \\
\text { Adriana }\end{array}$ & $\begin{array}{c}\text { Universidade } \\
\text { Federal do } \\
\text { Ceará }\end{array}$ & $\begin{array}{l}\text { Mestrado } \\
\text { profissional } \\
\text { em políticas } \\
\text { públicas e } \\
\text { gestão da } \\
\text { educação } \\
\text { superior }\end{array}$ & $\begin{array}{l}\text { Políticas Públicas } \\
\text { da Educação } \\
\text { Superior. }\end{array}$ & 2015 & Dissertação \\
\hline $\begin{array}{l}\text { CUNHA, } \\
\text { Márcio }\end{array}$ & $\begin{array}{c}\text { Universidade } \\
\text { Estadual do } \\
\text { Ceará }\end{array}$ & $\begin{array}{c}\text { Mestrado } \\
\text { profissional } \\
\text { em } \\
\text { planejamento } \\
\text { e políticas }\end{array}$ & $\begin{array}{l}\text { Avaliação de } \\
\text { instituições, } \\
\text { programas e } \\
\text { projetos } \\
\text { institucionais }\end{array}$ & 2015 & Dissertação \\
\hline
\end{tabular}


públicas

\begin{tabular}{|c|c|c|c|c|c|}
\hline $\begin{array}{l}\text { MEDEIROS, } \\
\text { Josiane }\end{array}$ & $\begin{array}{l}\text { Universidade } \\
\text { Federal de } \\
\text { Goiás - } \\
\text { Regional Jataí }\end{array}$ & Educação & $\begin{array}{c}\text { Políticas } \\
\text { Educacionais, } \\
\text { Gestão e } \\
\text { Formação de } \\
\text { Professores }\end{array}$ & 2015 & Dissertação \\
\hline $\begin{array}{l}\text { BARROS, } \\
\text { Alinic }\end{array}$ & $\begin{array}{c}\text { Universidade } \\
\text { Federal do } \\
\text { ABC }\end{array}$ & $\begin{array}{c}\text { Ensino e } \\
\text { história das } \\
\text { ciências e da } \\
\text { matemática }\end{array}$ & $\begin{array}{c}\text { Ensino, história e } \\
\text { filosofia das } \\
\text { ciências e } \\
\text { matemática }\end{array}$ & 2016 & Dissertação \\
\hline $\begin{array}{c}\text { FERNANDES, } \\
\text { Dimas }\end{array}$ & $\begin{array}{l}\text { Pontifícia } \\
\text { Universidade } \\
\text { Católica do } \\
\text { Rio de Janeiro }\end{array}$ & Educação & $\begin{array}{c}\text { Processos } \\
\text { culturais, } \\
\text { instâncias de } \\
\text { socialização e a } \\
\text { educação }\end{array}$ & 2016 & Dissertação \\
\hline $\begin{array}{l}\text { GEHRING, } \\
\text { Fernanda }\end{array}$ & $\begin{array}{l}\text { Universidade } \\
\text { Estadual do } \\
\text { Oeste do } \\
\text { Paraná }\end{array}$ & Letras & $\begin{array}{l}\text { Linguagem: } \\
\text { práticas } \\
\text { linguísticas, } \\
\text { culturais e de } \\
\text { ensino }\end{array}$ & 2016 & Dissertação \\
\hline
\end{tabular}

\begin{tabular}{|c|c|c|c|c|c|}
\hline $\begin{array}{c}\text { GONÇALVES, } \\
\text { Glaucia }\end{array}$ & $\begin{array}{l}\text { Pontifícia } \\
\text { Universidade } \\
\text { Católica de } \\
\text { São Paulo }\end{array}$ & Educação & $\begin{array}{l}\text { Processos } \\
\text { psicossociais na } \\
\text { formação e no } \\
\text { exercício } \\
\text { profissional de } \\
\text { educadores }\end{array}$ & 2016 & Tese \\
\hline LIMA, Sabrina & $\begin{array}{l}\text { Universidade } \\
\text { Federal de } \\
\text { Viçosa }\end{array}$ & Educação & $\begin{array}{l}\text { Educação pública: } \\
\text { sujeitos e práticas }\end{array}$ & 2016 & Dissertação \\
\hline $\begin{array}{l}\text { MALAQUIAS } \\
\text { Danielle, }\end{array}$ & $\begin{array}{c}\text { Instituto } \\
\text { Federal de } \\
\text { Educação, } \\
\text { Ciência e } \\
\text { Tecnologia do } \\
\text { Rio de Janeiro }\end{array}$ & $\begin{array}{l}\text { Ensino de } \\
\text { Ciências }\end{array}$ & $\begin{array}{l}\text { Formação de } \\
\text { professores de } \\
\text { ciências }\end{array}$ & 2016 & Dissertação \\
\hline $\begin{array}{l}\text { OBARA, } \\
\text { Cássia }\end{array}$ & $\begin{array}{l}\text { Universidade } \\
\text { Estadual de } \\
\text { Londrina }\end{array}$ & $\begin{array}{l}\text { Ensino de } \\
\text { ciências e } \\
\text { educação } \\
\text { matemática }\end{array}$ & $\begin{array}{c}\text { Formação de } \\
\text { professores em } \\
\text { ciências e } \\
\text { matemática. }\end{array}$ & 2016 & Dissertação \\
\hline $\begin{array}{l}\text { RODRIGUES, } \\
\text { Franciele }\end{array}$ & $\begin{array}{l}\text { Universidade } \\
\text { Estadual de } \\
\text { Londrina }\end{array}$ & $\begin{array}{l}\text { Ciências } \\
\text { Sociais }\end{array}$ & $\begin{array}{l}\text { Ensino de } \\
\text { sociologia }\end{array}$ & 2016 & Dissertação \\
\hline $\begin{array}{l}\text { SOMBRA, } \\
\text { Cíntia }\end{array}$ & $\begin{array}{l}\text { Universidade } \\
\text { Estadual do } \\
\text { Ceará }\end{array}$ & Educação & $\begin{array}{c}\text { Formação e } \\
\text { desenvolvimento } \\
\text { profissional em }\end{array}$ & 2016 & Dissertação \\
\hline
\end{tabular}




\begin{tabular}{|c|c|c|c|c|c|}
\hline & & & educação & & \\
\hline $\begin{array}{l}\text { DEMARI, } \\
\text { Jennifer }\end{array}$ & $\begin{array}{c}\text { Universidade } \\
\text { Federal do } \\
\text { Rio Grande } \\
\text { do Sul }\end{array}$ & $\begin{array}{c}\text { Educação em } \\
\text { ciências: } \\
\text { química da } \\
\text { Vida e saúde }\end{array}$ & $\begin{array}{c}\text { Educação } \\
\text { científica: } \\
\text { produção } \\
\text { científica e } \\
\text { avaliação de } \\
\text { produtividade em } \\
\text { ciência }\end{array}$ & 2017 & Dissertação \\
\hline
\end{tabular}

Fonte: Dados organizados pelas autoras, a partir de pesquisa encontrada no Banco de Teses e Dissertações da CAPES.

Martins (2013), dissertação no Programa de Pós-Graduação na Universidade Federal do Ceará - UFC, investigou os saberes pedagógicos construídos por egressos do PIBID do Curso de Ciências Biológicas da UFC, participantes do programa nos anos de 2009 a 2011 , em duas escolas públicas do município de Fortaleza, a partir de metodologias que os egressos desenvolveram para o ensino de Biologia. A pesquisa, caracterizada como qualitativa e exploratória, utilizou como método o estudo de caso. Os sujeitos da pesquisa foram sete egressos do PBID de Biologia da UFC que exerceram ou exercem a profissão no ensino básico. Para a coleta de dados, utilizou-se da entrevista semiestruturada e da análise documental bem como da análise de conteúdo para tratar das informações. O estudo apontou que existe influência do PIBID na prática docente dos egressos, porém muito daquilo que aprenderam, referente às metodologias de ensino, não puderam ser desenvolvidas na prática pedagógica, tendo em vista as condições de trabalho do professor.

Oliveira (2014), dissertação na Universidade Federal de São João Del-Rei - UFSJ, buscou compreender a contribuição do PIBID para os docentes egressos dos cursos de licenciatura da UFSJ a partir das experiências vivenciadas como bolsistas. Como instrumento de coleta de dados utilizou-se do questionário e da entrevista para levantar o perfil dos egressos, no intuito de conhecer os participantes da pesquisa, bem como sua área de atuação e se exerciam ou não a profissão escolhida. Como resultados, os egressos consideram o PIBID como um programa motivador para optar pela docência e, ao mesmo tempo, importante para a prática do professor, pois propicia inovação metodológica e possibilita a relação entre educação básica e ensino superior.

Olivera (2014), dissertação no Programa de Pós-Graduação da Universidade Federal de Ouro Preto - UFOP, investigou se o PIBID da instituição conseguiu alcançar seu objetivo em incentivar a formação de professores para a educação básica. A pesquisa contou com a participação de 16 professores egressos do programa que participaram respondendo 
questionário e entrevista. Os resultados apontaram para a contribuição do programa na formação dos egressos, mediante ações que asseguram o fortalecimento de práticas pedagógicas, dos saberes docentes e do desenvolvimento de habilidades. Apontou igualmente que o PIBID contribui para que a universidade pudesse discutir a formação de professores. Por outro lado, apresenta algumas falhas em sua execução, destacando a necessidade de se pensar em ações e projetos que melhorem a efetivação do programa.

Silva (2014), dissertação na Universidade Federal de São Carlos - UFSCar, desenvolveu pesquisa junto aos egressos do PIBID na área de Matemática da mesma instituição. Procurou compreender as percepções dos egressos no processo de iniciação à docência, identificando as contribuições e limitações do processo formativo na carreira docente. A autora mapeou os bolsistas que participaram do PIBID, contabilizando 35 participantes no período de três anos com seus subprojetos. Como instrumento de pesquisa fez-se uso de questionário para traçar o perfil dos bolsistas egressos, identificando se optaram pela docência. Com esse critério de seleção, analisou os portfólios de cinco bolsistas enquanto participação no PIBID, no intuito de identificar as principais atividades desenvolvidas no programa. No aprofundamento dos dados, contou com a participação de mais quatro participantes na realização de entrevista, a fim de identificar as percepções dos egressos sobre seu processo de formação, a entrada na profissão docente e as perspectivas futuras. Os resultados apontaram para fatores positivos, pois o programa propiciou a relação entre teoria e prática aos licenciandos, procurando a superação entre a matemática escolar e a matemática acadêmica da formação inicial.

Araújo (2015), dissertação no programa de pós-graduação da Universidade Federal do Ceará - UFC, avaliou o PIBID na formação e qualificação de professores da educação básica, identificando a influência do programa na escolha da profissão segundo a perspectiva dos egressos. Como metodologia a pesquisa foi caracterizada como exploratória e estudo de caso. O instrumento de coleta de dados foi o questionário, enviado para endereço eletrônico de 584 egressos do PIBID da UFC, obtendo retorno de 14,38\% da população pesquisada. Os resultados mostraram que o programa contribuiu para formação de professores e despertou ou reforçou o interesse pela profissão. Segundo a pesquisadora, é preciso outras pesquisas para avaliar as contribuições do PIBID na perspectiva dos egressos, levando em conta outras instituições de diferentes localidades.

Cunha (2015), dissertação na Universidade Estadual do Ceará - UEC, analisou o subprojeto do PIBID da Licenciatura em Matemática, do Campus Crateús do Instituto 
Federal do Ceará de Educação, Ciência e Tecnologia - IFCE, a fim de verificar a estruturação do projeto e sua contribuição na formação inicial dos egressos. A pesquisa de cunho documental, contou com a observação participante e questionário on.line. Participaram da pesquisa cinco egressos, ex-bolsistas da licenciatura em matemática. Os dados levantados revelaram que o PIBID contribui para formação inicial ao estabelecer relação entre teoria e prática, além de estimular o desenvolvimento de práticas inovadoras.

Medeiros (2015), dissertação no Programa de Pós-Graduação em Educação na Universidade Federal de Goiás - UFG, Regional Jataí, analisou o PIBID no Instituto Federal de Educação, Ciência e Tecnologia Goiano - Câmpus Rio Verde (IF Goiano RV), apontando os avanços, limites, desafios, perspectivas e o papel do PIBID na formação do docente de Ciências. Como metodologia, fez-se uso do questionário para 16 licenciandos bolsistas que atuam no PIBID, 10 professores supervisores da Educação Básica do PIBID do IF Goiano RV e 12 bolsistas egressos. Dos resultados, destacam-se os limites e as possibilidades representados pelo PIBID; possibilidades por relacionar teoria e prática, como a relação entre instituições de ensino superior e instituições de Educação Básica. Os limites encontram-se na falta da valorização da carreira docente, falta de estímulo aos professores, problemas com a percepção da gestão escolar sobre o programa.

Barros (2016), dissertação na Universidade Federal do ABC - UFABC, investigou as contribuições do PIBID aos egressos da instituição. Os participantes da pesquisa foram sete egressos que participaram do PIBID nos cursos de licenciatura da instituição. Utilizou-se da entrevista como metodologia e, como fundamento de análise, a teoria da AD - Análise do Discurso. Os resultados mostraram que o programa alcançou seus objetivos nos subprojetos de física, química, biologia e matemática no período de 2010 a 2012, contribuindo para a qualidade da formação inicial de professores, a partir das experiências vivenciadas na prática, permitindo autonomia dos egressos no trabalho docente.

Fernandes (2016), dissertação realizada no Programa de Pós-Graduação em Educação na Pontifícia Universidade Católica do Rio de Janeiro - PUC/RJ, verificou os impactos do PIBID na carreira e na trajetória profissional, na área de Filosofia no estado do Rio de Janeiro. Investigou o programa em cinco universidades em que se discutiu o desejo pela carreira docente a partir da percepção dos egressos que participaram do PIBID. Como procedimento metodológico a pesquisa contou com 31 entrevistas. Os resultados obtidos, ao contrário do esperado, revelaram que a estrutura educacional considerada o programa de forma isolada, no qual desvaloriza o trabalho docente, as pesquisas e a formação de 
professores para o ensino. Os vetores que influenciam na escolha e preferência pela carreira acadêmica em detrimento à docência entram em contradição com os objetivos do PIBID, sendo um deles o incentivo ao magistério.

Gehring (2016), dissertação na Universidade Estadual do Oeste do Paraná Unioeste, reflete os impactos do PIBID na formação inicial de 11 egressos do subprojeto de Letras/ Língua Portuguesa entre 2011-2014 da Unioeste - Câmpus de Marechal Cândido Rondon - PR. A pesquisa fez uso de entrevistas semiestruturadas. Os dados apontaram para os impactos da aproximação entre universidade e escola, relação entre teoria e prática e a interação entre bolsista e o aluno da educação básica.

Gonçalves (2016), tese na Pontifícia Universidade Católica de São Paulo - PUC/SP, analisou a inserção profissional de egressos do PIBID. A investigação foi desenvolvida por meio de grupos de discussão com 12 professoras iniciantes e egressas do PIBID, do curso de Pedagogia de uma universidade pública federal do estado de Minas Gerais. Utilizou-se de questionário para a caracterização pessoal e profissional dos participantes da pesquisa, além de entrevista semiestruturada com sete diretoras e supervisoras das escolas básicas onde atuam as professoras iniciantes e da análise documental do projeto político pedagógico da instituição formadora. Os resultados mostraram que a inserção dos profissionais na profissão foi permeada por dificuldades, tensões, descobertas e aprendizagem, revelando também que a formação inicial realizada no curso de Pedagogia e a participação no PIBID foram importantes para a inserção profissional.

Lima (2016), dissertação no programa de pós graduação na Universidade Federal de Viçosa -UFV, objetivou compreender a influência do PIBID sob a percepção de egressos do curso de Educação Física de uma universidade mineira, ao escolherem a escola como campo de atuação profissional. Fez-se uso de questionário e entrevista. Os dados revelam que maioria dos entrevistados apresenta o PIBID como uma experiência significativa e a inserção no contexto escolar seria uma contribuição importante do programa. A autora afirma que participar do PIBID não garantiu que os bolsistas escolhessem a escola como lócus de atuação após concluir o ensino superior, pois a maioria deles atua nas áreas de bacharelado e que as condições de trabalho e a desvalorização da educação física escolar desestimulam os egressos a atuar no ensino público.

Malaquias (2016), dissertação no Instituto Federal de Educação, Ciência e Tecnologia do Rio de Janeiro - IFRJ, analisou as contribuições do PIBID na formação acadêmica e na atuação como docente, dos alunos egressos da licenciatura em Química do IFRJ do campus 
Nilópolis. A pesquisa fez uso de questionário e entrevista. Os resultados mostraram que para os egressos o programa é importante na formação acadêmica, uma vez que minimiza o medo de lecionar; $50 \%$ dos egressos têm o desejo de continuar na docência; $50 \%$ dos egressos estão na docência e procuram levar para o seu trabalho as propostas metodológicas desenvolvidas no PIBID, outros 50\% decidiram seguir os estudos em cursos de pós-graduação.

Obara (2016), dissertação na Universidade Estadual de Londrina - UEL, analisou as contribuições do PIBID para a construção da identidade do professor, contando com a contribuição de ex-bolsistas do PIBID, egressos do curso de Química da UEL e atuantes na profissão docente. Como procedimento metodológico utilizou-se da análise textual discursiva. A análise realizada com cinco participantes mostrou que daqueles que falaram sobre a reflexão na docência têm maior experiência na docência. Quatro sujeitos tiveram menor manifestação em conhecimento prático no qual considerou curto período profissional após participar no PIBID, mas o interesse pela docência e a identidade docente estiveram presentes nas falas dos sujeitos, o que evidenciou o processo de construção da identidade profissional como contribuição do PIBID. Os sujeitos pesquisados relacionaram sua carreira docente como profissionais, considerando a atuação no PIBID, apontando como um momento de aprendizagem didático-pedagógica e isso influenciou os sujeitos entrevistados a permanecerem na profissão docente.

Rodrigues (2016), dissertação na Universidade Estadual de Londrina - UEL, analisou como o PIBID tem trazido mudanças na formação de professores na área da educação. A pesquisa teve as percepções de participantes do programa (coordenadores de área, professores supervisores e egressos) da UEL, no período de 2010 a 2016. Como instrumento de pesquisa utilizou o questionário on.line com 12 coordenadores de área e 10 egressos, entrevista com duas supervisoras do programa na área de matemática e acompanhou aulas de duas egressas em duas escolas públicas dos municípios de Londrina/PR e Cambé/PR, as quais participaram do PIBID nas áreas de Ciências Sociais e Matemáticas, bem como de duas professoras experientes nas mesmas áreas. Os dados apontaram a ressignificação das licenciaturas da UEL e o papel do professor da escola na qualificação de novos professores tem levado aos docentes escolherem o campo da educação. Os professores da universidade, da escola e os estudantes da graduação e pós-graduação se encontram mais dispostos a agir na área escolar e nas universidades na busca de uma formação profissional qualificada.

Sombra (2016), dissertação na Universidade Estadual do Ceará- UECE, buscou compreender as contribuições do PIBD da UECE, nas áreas de Ciências Biológicas, Física e 
Química para a atuação e permanência da docência dos pibidianos. A pesquisa contou com a participação de 55 licenciandos participantes do PIBID. Como metodologia, utilizou-se questionário eletrônico com 19 questões. Os resultados revelaram que 31 estavam trabalhando na docência durante a coleta de dados e 21 pretendiam continuar na docência; 19 egressos pretendiam atuar na docência e 24 afirmaram que o PIBID contribuiu para o início do trabalho docente. A autora destaca que o programa auxiliou na inserção profissional dos egressos e aumentou a segurança dos professores iniciantes em relação à gestão da sala de aula. As motivações para a não atuação na docência devem-se à desvalorização e ao estresse da profissão docente.

Demari (2017), dissertação no programa de pós-graduação da Universidade Federal do Rio Grande do Sul - UFRGS, objetivou analisar as contribuições do PIBID de Química da UFRGS na formação docente, segundo a perspectiva dos egressos, e verificar a atuação dos egressos ao saírem do programa. A pesquisa teve a participação de 32 egressos do subprojeto de Química da UFRGS de 2009 a 2014, usando como instrumento de coleta o questionário eletrônico com 13 questões. Do total de participantes, 19 egressos concluíram o curso de licenciatura em Química na UFRGS e o restante ainda não; 40\% dos egressos atuam na educação básica. Alguns entrevistados alegaram que deixaram de atuar na educação básica devido às péssimas condições no ambiente escolar. Os dados ainda revelaram que o PIBID contribuiu na formação dos egressos, pois possibilitou ao graduando o contato com a realidade escolar, além de desenvolver novas práticas escolares, o que proporcionou maior segurança para atuar na profissão.

\section{A análise dos dados}

A identificação das produções no período de 2013 a 2017 sobre o PIBID permite verificar que as pesquisas, que discutem a contribuição do programa na formação dos egressos, deram-se em vários programas de pós-graduação e em diferentes linhas de pesquisa. A área que predominou foi a educação, com total de oito produções, sendo sete dissertações e uma tese. O gráfico 1 ilustra a quantidade de pesquisas por período de publicação. 


\section{Gráfico 1- Distribuição de Teses e Dissertações no período de 2013 - 2017}

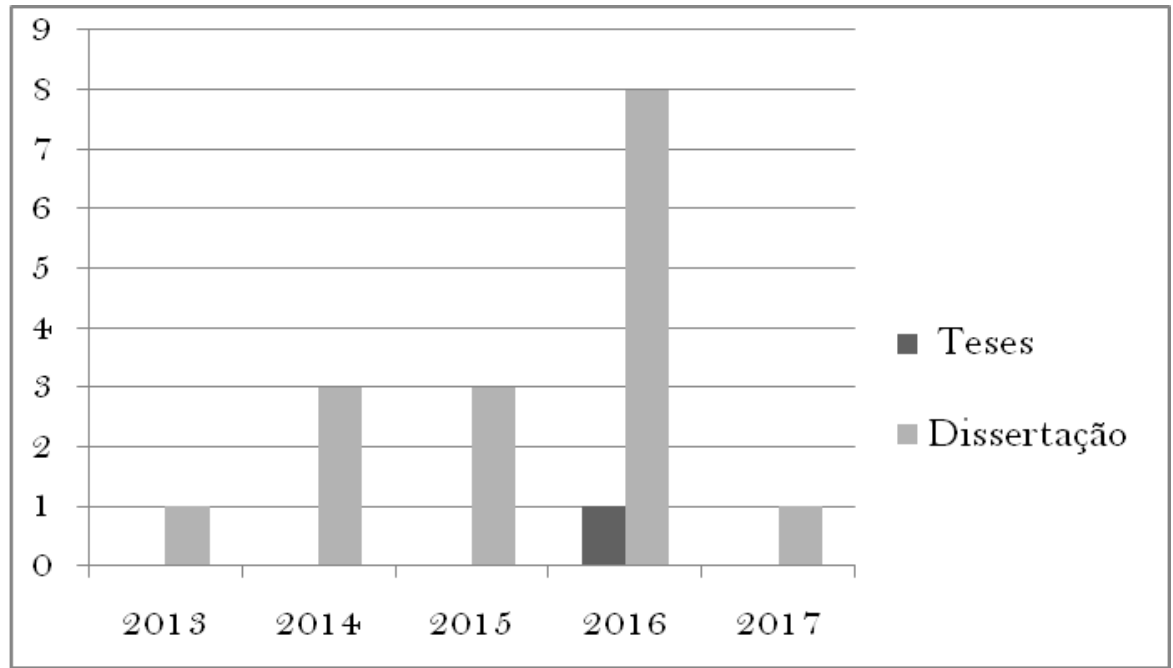

Fonte: Dados organizados pelas autoras, a partir de pesquisa encontrada no Banco de Teses e Dissertações da CAPES.

Este levantamento mostra a predominância das dissertações. Observa-se um crescimento das produções em 2016, totalizando oito dissertações e uma tese. Em seguida, os anos de 2014 e 2015 com três produções em cada ano. Em 2013 e 2017 foram duas pesquisas científicas, uma para cada ano.

É importante destacar que no ano de 2016 o PIBID, sendo um programa considerado importante para formação inicial e continuada de professores, apresenta alguns retrocessos, uma vez que esteve submetido a cortes orçamentais no ano de 2015 que até comprometeu a permanência do programa. Por esse motivo, pode-se inferir que houve maior interesse nesse período em pesquisar o programa, já que seria importante mostrar à sociedade suas contribuições na formação de professores.

Quanto à distribuição da pesquisa sobre o PIBID, no período de 2013 a 2017 observase, conforme o gráfico 2 , que as dissertações e tese selecionadas foram defendidas em maior parte na Região Sudeste com sete dissertações e uma tese, totalizando oito pesquisas. A Região Sul e Nordeste com o total de quatro dissertações para cada região. A Região CentroOeste com uma dissertação. Um ponto a destacar é que na Região Norte nenhuma pesquisa foi produzida durante esse período. 
Gráfico 2- Quantidade de pesquisas por Regiões do Brasil

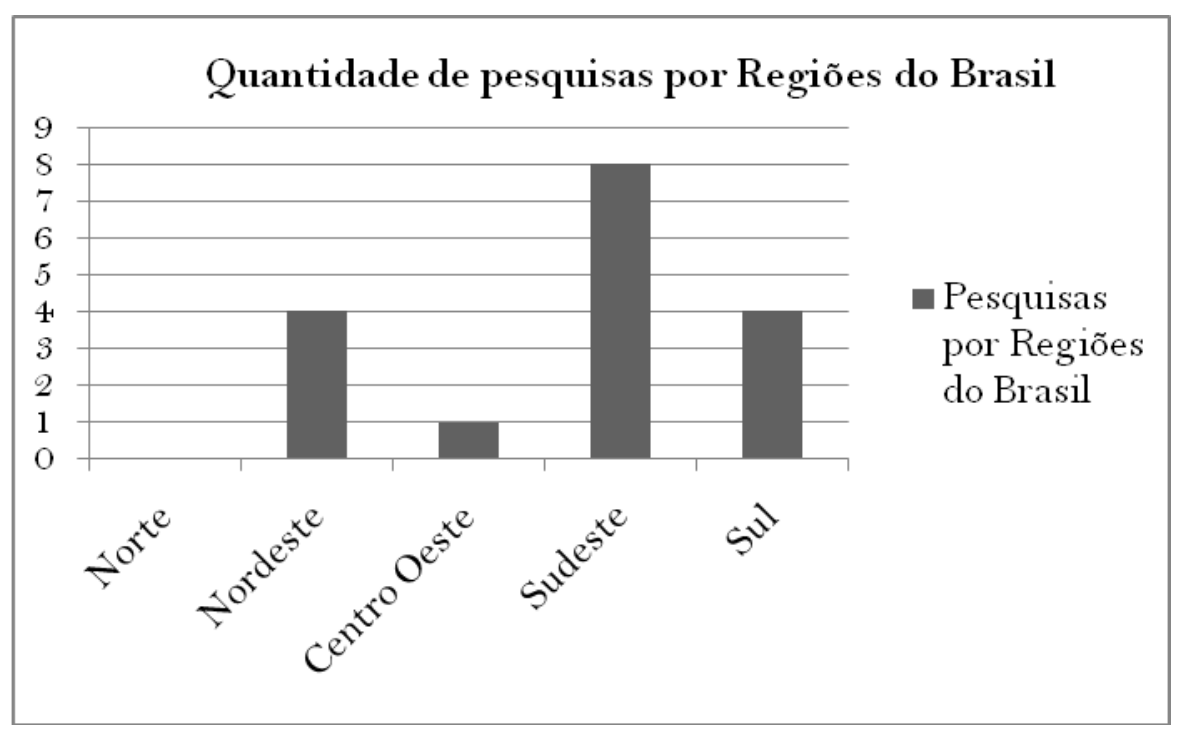

Fonte: Dados organizados pelas autoras, a partir de pesquisa encontrada no Banco de Teses e Dissertações da CAPES.

A Tabela 2, abaixo, evidencia que a região Sudeste apresenta maior número de produções nas instituições de ensino superior, com 8 pesquisas na região, destaques para Minas Gerais e São Paulo com três produções respectivamente, enquanto que a Região centro Oeste, estado de Goiás, com uma produção científica.

Tabela 2- Dissertações e teses sobre PIBID por Instituição de Ensino Superior

\begin{tabular}{cc}
\hline Instituição de Ensino Superior & Quantidade Trabalhos \\
\hline UFABC/São Paulo & 1 \\
UFC/ Fortaleza -Ceará & 2 \\
UEC/ Fortaleza - Ceará & 2 \\
UFG / Jataí -Goiás & 1 \\
UEL/ Londrina - Paraná & 2 \\
UNIOESTE/ Cascável - Paraná & 1 \\
UFOP/ Mariana - Minas Gerais & 1 \\
UFRGS/ Porto Alegre - Rio Grande do & 1 \\
IFRJ / Rio de Janeiro & 1 \\
UFSCar/ São Paulo & 1 \\
UFSJ/ Minas Gerais & 1 \\
UFV / Viçosa - Minas Gerais & 1 \\
\hline
\end{tabular}




\begin{tabular}{cc}
\hline PUC Rio/ Rio de Janeiro & 1 \\
PUC/SP São Paulo & 1 \\
\hline
\end{tabular}

Fonte: Dados organizados pelas autoras, a partir de pesquisa encontrada no Banco de Teses e Dissertações da CAPES.

Tratando-se da distribuição das produções científicas por universidade, observou-se que as universidades públicas possuem maior número de pesquisas no nível de pósgraduação.

\section{Gráfico 3- Pesquisas por Instituições de Ensino Superior}

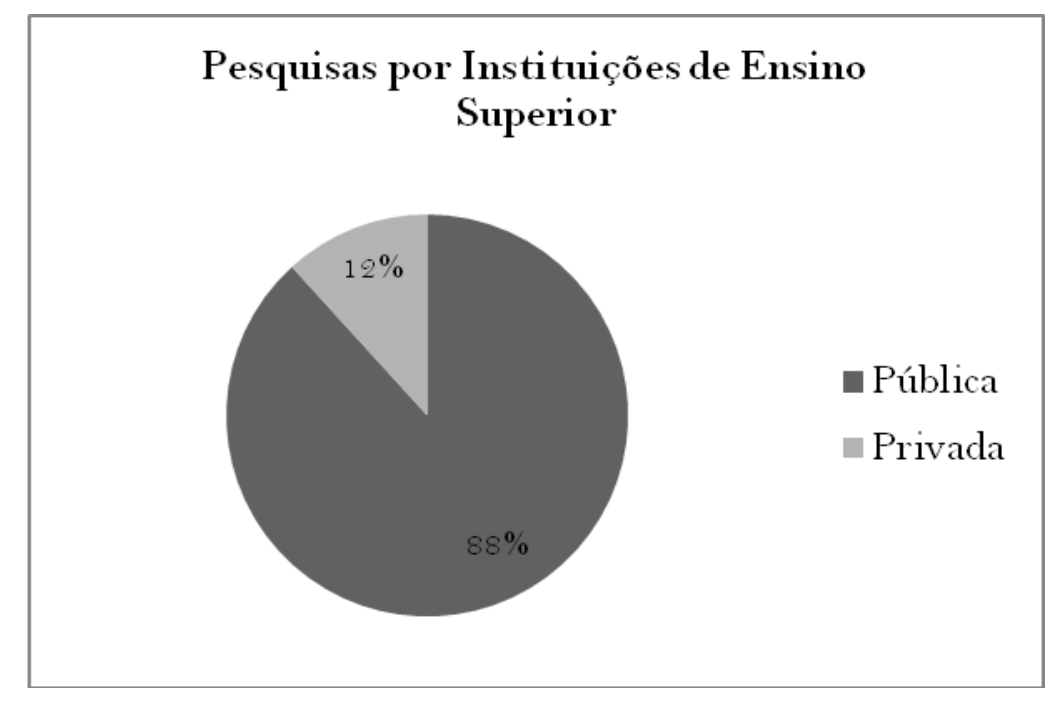

Fonte: Dados organizados pelas autoras, a partir de pesquisa encontrada no Banco de Teses e Dissertações da CAPES.

O gráfico 3 apresenta maior ocorrência de produções científicas nas universidades públicas, totalizando 15 dissertações que representam $88 \%$ das pesquisas. Já nas universidades privadas têm-se 2 pesquisas, sendo uma dissertação e uma tese, um porcentual de $12 \%$.

Quanto aos resultados apresentados nas dissertações e teses encontradas, destaca-se praticamente que todas as pesquisas mencionam em seus resumos aspectos positivos do programa, afirmando a participação do PIBID como contribuição para formação dos egressos.

Sintetizando os resultados apresentados pelos autores nas pesquisas sobre o PIBID, destacam-se pontos positivos e negativos. Quanto aos positivos tem-se a influência do programa na prática docente dos egressos que atuam na educação básica; o elo entre teoria e prática; a utilização de metodologias inovadoras; a mediação entre universidade e escola; a 
qualificação na formação inicial de professores; as atividades no programa desencadeadoras de autonomia; o auxílio no desenvolvimento de habilidades dos egressos; a permanência do bolsista na profissão docente; a maior segurança para atuar na profissão; a interação entre licenciando e o aluno da educação básica; o conhecimento da realidade escolar pelos licenciandos.

Quanto aos aspectos negativos, seriam as limitações do PIBID, tais como: a desvalorização da profissão docente, um dos motivos para que os licenciados não queiram continuar na docência, também o não desejo de permanecer na docência em razão do estresse vivenciado na profissão e das condições de trabalho. Os resultados também indicaram que alguns egressos optaram em aperfeiçoar a formação em cursos de pós-graduação e que se faz necessário pensar em ações que melhorem a qualidade do programa.

A partir dos resultados identificados nas pesquisas, pode-se destacar que o programa contribui na formação inicial de professores, mas, devido a problemas encontrados no contex to educacional, alguns egressos perdem o interesse em continuar na docência.

Estudo realizado por Gatti et.al (2014) sobre o PIBID nas cinco regiões do Brasil: Norte, Nordeste, Centro-Oeste, Sudeste e Sul mostra dentre os resultados a contribuição do programa na formação dos bolsistas. Isso corrobora em parte as percepções das pesquisas consultadas a partir do levantamento pelo banco de dados de teses e dissertações da CAPES. Porém, se para Gatti et.al (2014) o programa possibilita o contato direto dos bolsistas com a escola pública; a relação entre teoria e prática; a criatividade dos bolsistas para construir materiais didáticos e pedagógicos; o fomento à investigação; a valorização da formação de professores e formação de qualidade para os bolsistas, por outro lado, o levantamento das pesquisas evidencia a precarização do trabalho docente, as péssimas condições de trabalho e a desvalorização docente, fatores que impossibilitam a permanência dos egressos na docência. Fernandes (2016) vai mais longe em suas críticas, pois considera que o PIBID não cumpre com seus objetivos primários que são o incentivo à docência, pesquisa e formação.

\section{Considerações finais}

Os dados coletados a partir do estado do conhecimento, disponibilizado pelo Banco de Teses e Dissertações da CAPES, indicaram 37 pesquisas sobre PIBID, mas somente 17 abordaram a contribuição do programa na formação dos egressos. Um aspecto identificado na investigação é que a região Sudeste destaca-se com um maior quantitativo de pesquisas e, 
por outro lado sinaliza para o fato de que a região Norte não tem publicação sobre o PIBID e suas contribuições na formação dos egressos. Os dados ainda revelam que houve maior número de produção em nível de dissertação, no ano de 2016. Outro aspecto verificado, a maioria das pesquisas foi realizada em universidades públicas. As análises também permitiram identificar que o programa contribui para formação inicial de professores, levando boa parte dos egressos a permanecer na docência, porém apresenta algumas limitações no que diz respeito à desvalorização da profissão e à falta de condições de trabalho.

\section{Referências}

ANPED. Entidades se posicionam contrárias... Disponível em:

$<$ http://www.anped.org.br/news/entidades-se-posicionam-contrarias-padronizacao-econtrole-impostos-pelo-programa-de-residencia > Acesso em: 06 mar. 2018.

ARAÚJO, Adriana Castro. Avaliação do Programa Institucional De Bolsa De Iniciação À Docência da Universidade Federal Do Ceará na perspectiva dos egressos. 2015.98 f. Dissertação (Mestrado em profissional em Políticas Públicas e Gestão da Educação Superior). Universidade Federal do Ceará, Fortaleza. 2015.

BARROS, Alinic Vieira De. Contribuições do programa institucional de bolsas de iniciação à docência para a formação inicial dos egressos das licenciaturas da Universidade Federal do ABC. 2016. 160 p. Dissertação (Mestrado em Ensino e História das Ciências e da Matemática Instituição de Ensino), Universidade Federal do ABC, São Paulo. 2016.

BRASIL. Decreto n. ${ }^{\circ} 6.755$, de 29 de janeiro de 2009. Institui a Política Nacional de Formação de Profissionais do Magistério da Educação Básica, disciplina a atuação da Coordenação de Aperfeiçoamento de Pessoal de Nível Superior- Capes no fomento a programas de formação inicial e continuada e dá outras providências. Disponível em: <http://www.planalto.gov.br/ccivil_03/_ato2007-

2010/2009/decreto/D6755impressao.htm>. Acesso em: 15 mar. 2017.

BRASIL. O Plano de Desenvolvimento da Educação: razões, princípios e programas. Brasília: MEC, 2008.

BRASIL. Portaria normativa $n^{0}$ 38, de 12 de dezembro de 2007. Dispõe sobre o Programa de Bolsa Institucional de Iniciação à Docência - PIBID. Brasília: Ministério da Educação. Disponível em: <http://portal.mec.gov.br/arquivos/pdf/portaria_pibid.pdf>. Acesso em: 10 fev. 2018.

BRASIL. Portaria $n^{o}$ 096, de 18 de julho de 2013. Programa Institucional de Bolsa de Iniciação à Docência - PIBID. Educação básica. . Brasília: Ministério da Educação Disponível em: https://www.capes.gov.br/images/stories/download/legislacao/Portaria_096_18jul13_Apr ovaRegulamentoPIBID.pdf . Acesso em: 20 dez. 2017. 
CUNHA, Marcio Monteiro. O PIBID sob a perspectiva de seus egressos: estudo exploratório de uma política pública de formação de professores. 2015. 100 f. Dissertação (Mestrado Profissional em Planejamento e Politicas Públicas Instituição de Ensino), Universidade Estadual do Ceará, Fortaleza. 2015.

DEMARI, Jennifer. A formação docente no Pibid/Química da UFRGS na perspectiva dos egressos do Programa. 2017. 61 f. Dissertação (Mestrado em Educação em Ciências Química Da Vida E Saúde), Universidade Federal Do Rio Grande Do Sul. Porto Alegre. 2017.

FERNANDES, Dimas Augusto Martorello. Aspirações de carreira dos estudantes egressos do PIBID-Filosofia da região do Grande-Rio: pesquisa de campo sobre a formação para o ensino de Filosofia no RJ. 2016. 106 f. Dissertação (Mestrado em Educação Instituição de Ensino), Pontifícia Universidade Católica do Rio de Janeiro. Rio de Janeiro. 2016.

FERREIRA, Norma Sandra de Almeida. As pesquisas denominadas "Estado da Arte". Educação छे Sociedade, vol. 23, n. 79, 2002. p. 257 - 272. Disponível em: <http: www.scielo.br/pdf/es/v23n79/10857.pdf>. Acesso em: 26 fev. 2018.

GATTI, Bernardete Angelina et. al. Políticas docentes no Brasil: um estado da arte. Brasília: UNESCO, 2011.

GATTI, Bernadete Angelina et al. Um estudo avaliativo do programa institucional de bolsa de iniciação à docência (pibid). São Paulo: FCC/SEP: Fundação Carlos Chagas, 2014.

GEHRING, Fernanda Maria Muller. Formação inicial de professores de Língua Portuguesa: retratos e reflexos do PIBID. 2016. 227 f. Dissertação (Mestrado em Letras), Universidade Estadual do Oeste do Paraná, Paraná. 2016.

GONCALVES, Glaucia Signorelli de Queiroz. Inserção profissional de egressos do PIBID: desafios e aprendizagens no inicio da docência. 2016. 243 f. Tese (Doutorado em Educação) Pontifícia Universidade Católica De São Paulo. São Paulo. 2016.

GUARDA. Juliana Alves da; RAIMANN, Elizabeth Gottschalg. Programa Institucional de Bolsas a Iniciação a Docência: possibilidades e limites. Cad. Ed. Tec. Soc., Inhumas, v.9, n.1, 2016. p. 82-94, 2016. Disponível em: <www.brajets.com/index.php/brajets/article/download/298/163>. Acesso em: 26 fev. 2018.

LIMA, Sabrina Aparecida de. A atratividade da carreira docente: uma análise na perspectiva de ex-bolsistas do PIBID do curso de Educação Física. 2016. 186 f. Dissertação (Mestrado em Educação), Universidade Federal de Viçosa. Minas Gerais. 2016.

MALAQUIAS, Danielle Silva Lima. A contribuç̧ão do PIBID na formação acadêmica dos licenciados em Química do IFRJ - Campus Nilópolis. 2016. 134 f. Dissertação (Mestrado em Ensino de Ciências), Instituto Federal De Educação, Ciência e Tecnologia do Rio de Janeiro, Rio de Janeiro. 2016.

MARTINS, Maria Marcia Melo De Castro. Saberes pedagógicos e o desenvolvimento de metodologias de ensino de Biologia: o Pibid como elemento de construção. 2013.229 f. Dissertação 
(Mestrado Profissional em Ensino De Ciências e Matemática) Universidade Federal do Ceará, Ceará. 2013.

MEDEIROS, Josiane Lopes. O PIBID e a formação do professor de Ciências no Instituto Federal Goiano - Câmpus Rio Verde: avanços, limites e perspectivas. 2015. 196 f. Dissertação (Mestrado em Educação) Universidade Federal de Goiás, Goiás. 2015.

OBARA, Cassia Emi. Contribuições do PIBID para a construção da identidade docente do professor de Química. 2016. 175 f. Dissertação (Mestrado em Ensino de Ciências e Educação Matemática), Universidade Estadual de Londrina, Londrina. 2016.

OLIVEIRA, Maximiliano Colper Soares De. Sentidos Do Programa Institucional De Bolsa de Iniciação à Docência (Pibid) na formação de professores: um estudo com egressos da Universidade Federal de São João Del - Rei. 2014. 121 f. Dissertação (Mestrado em Processos Socioeducativos e Práticas Escolares), Universidade Federal de São João Del-Rei, São João Del-Rei. 2014.

OLIVERI, Andressa. Maris. Rezende. Políticas de formação de professores no Brasil: um estudo sobre o PIBID na região dos Inconfidentes - MG. 2014. $161 \mathrm{f}$. Dissertação (Mestrado em Educação), Universidade Federal de Ouro Preto, Mariana. 2014.

RODRIGUES, Franciele. Afinal, o que faz o Programa de Iniciação à Docência - PIBID? Um estudo sobre a formação de professores na UEL, 2010-2016. 2016. 198 f. Dissertação (Programa de Pós-Graduação em Ciências Sociais), Universidade Estadual de Londrina, Londrina. 2016.

SILVA, Danielli Ferreira. Processo de iniciação à docência de professores de matemática: olhares de egressos do PIBID/UFSCar. 2014. 159 f. Dissertação (Mestrado em Educação), Universidade Federal de São Carlos, São Carlos. 2014.

SOMBRA, Cintia Goncalves. Egressos do PIBIB/UECE dos subprojetos de Ciências Biológicas, Física e Química: onde atuam e o que pensam sobre a permanência na docência? $2016100 \mathrm{f}$. Dissertação (Mestrado em Educação), Universidade Estadual do Ceará. Ceará. 2016. 